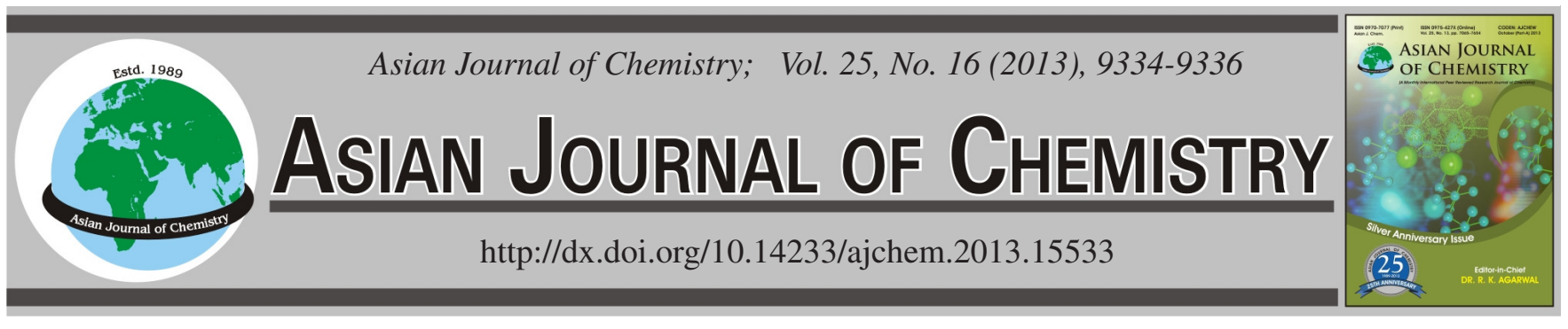

\title{
Effect of Different Substituents on Geometrical Structure of [60] Fullerene Derivatives
}

$$
\text { YAN-HuA CAI }{ }^{1,2, *}
$$

${ }^{1}$ School of Materials and Chemical Engineering, Chongqing University of Arts and Sciences, Yongchuan, Chongqing 402160, P.R. China ${ }^{2}$ Chongqing Key Laboratory of Micro/Nano Materials Engineering and Technology, Chongqing University of Arts and Sciences, Yongchuan, Chongqing 402160, P.R. China

*Corresponding author: E-mail: caiyh651@yahoo.com.cn

Effect of different substituents on geometrical structure of [60] fullerene derivatives was investigated by Dmol3. The results indicated that LUMO of three [60] fullerene derivatives mainly focued on [60] fullerene and degree of concentration of LUMO decreased with increasing of substituent number. However, the HOMO of [60] fullerene derivatives did not only focus on [60] fullerene and the HOMO moved other group. The value of energy gaps $\Delta \mathrm{E}$ was the largest when [60] fullerene without substituents and the $\Delta \mathrm{E}$ was the smallest when the substituents number of pyrrolidine of [60] fullerene derivatives was the most, the value was $0.053347 \mathrm{eV}$. The variety of bond length and angle of [60] fullerene derivatives were affected by substituents.

Key Words: [60] fullerene, Geometrical structure, Substituents.

ᄂ - - - - - - - - - - - - - - - - - - - - - - - - - -

\section{INTRODUCTION}

[60] fullerene has attracted more and more interest since [60] fullerene was found and [60] fullerene was widely used in materials sciences ${ }^{1}$, chemical sciences ${ }^{2}$, bio-sciences ${ }^{3}$, etc. due to its unique geometrical structure. In order to further wide the appication of [60] fullerene, more and more [60] fullerene derivatives were synthesized by chemical modification. However, there existed a little literature about the geometrical structure of [60] fullerene derivatives. The geometrical structure is very important to know the properties of [60] fullerene derivatives and wide the application of [60] fullerene derivatives. Belosludov et al. ${ }^{4}$ reported that the complex of hydroquinone and $\mathrm{C}_{60}$ has been studied by $a b$ initio and lattice dynamics calculations. These results showed that the equilibrium geometry of $\mathrm{C}_{60}$ in the cage was similar to the geometry of the isolated $\mathrm{C}_{60}$ and no charge transfer occured. The geometrical structures of $\mathrm{N} @ \mathrm{C}_{60}{ }^{*} \mathrm{FeCp}$ were investigated. there existed two isomers with the energy difference of $0.13 \mathrm{eV}$, one is that the encased nitrogen atom is located at the center of the fullerene cage. The Fe atom is $\eta^{5}$-coordinated to both $\mathrm{Cp}$ and $\mathrm{R}^{*}$. The another is that the atom is coordinated to $\mathrm{R}^{*}$ with $\eta^{4}$ hapticity and the nitrogen atom is bonded to a carbon atom of the $\mathrm{R} *$ ring in the other isomer ${ }^{5}$.

In this paper, in order to confirm the geometrical structure of [60] fullerene derivatives and effect of substituents on geometrical structure of [60] fullerene derivatives, we investigate

the geometrical structure of three [60] fullerene derivatives with different substituents.

\section{THEORETICAL CALCULATION METHOD}

Three [60] fullerene derivatives with different substituents were labled as A, B, C (Fig. 1). The theoretical calculation was performed using Dmol3 and the calculation quality was fine and use symmetry.

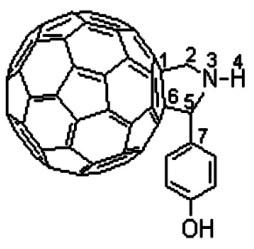

A

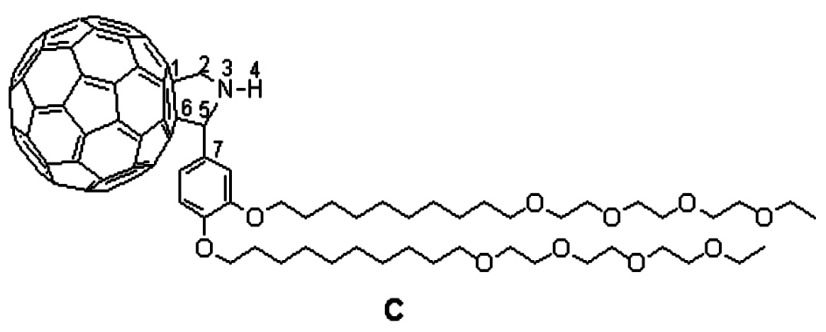

Fig. 1. Three [60] fullerene derivatives with different substituents 


\section{RESULTS AND DISCUSSION}

Optimization structure of [60] fullerene derivatives: The optimization structure of [60] fullerene derivatives were showed in Fig. 2 and the relative energies and the energy gaps between the highest occupied molecular orbital (HOMO) and the lowest unoccupied molecular orbital (LUMO) were calculated (Figs. 3 and 4). As shown in Fig. 3, LUMO of three [60] fullerene derivatives with different substituents mainly focus on [60] fullerene and degree of concentration of LUMO decreases with increasing of substituent number. However, the HOMO of substituents [60] fullerene derivatives do not only focus on [60] fullerene and the HOMO moves other group such as the benzene and pyrrolidine. HOMO in benzene and pyrrolidine increases with increasing of substituent number.

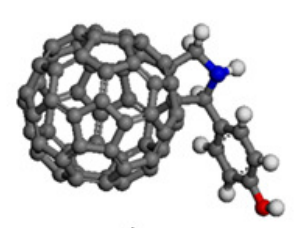

A

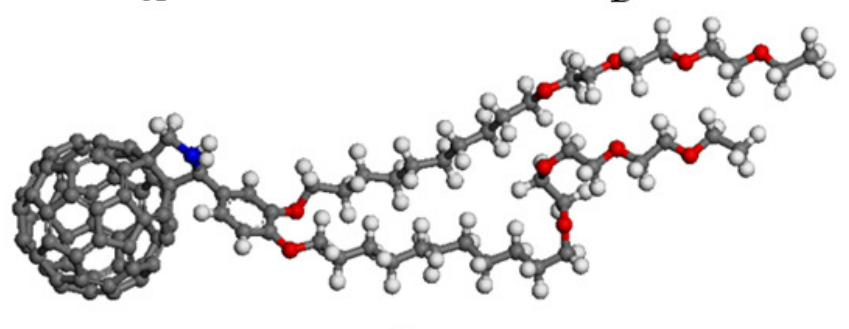

$\mathrm{C}$

Fig. 2. Optimized geometrical structure of three [60] fullerene derivatives with different substituents

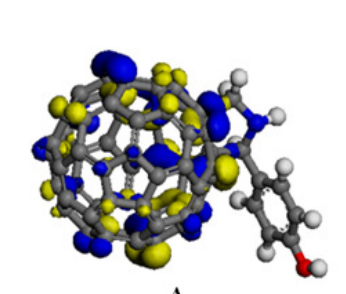

A

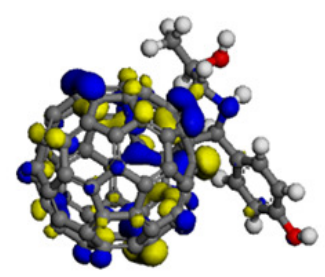

B

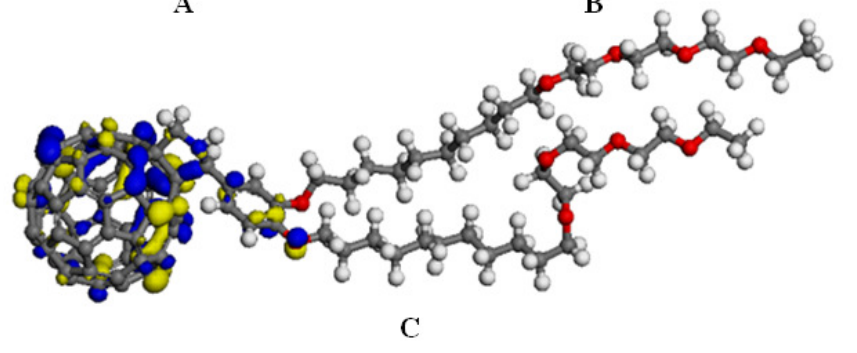

Fig. 3. HOMO of three [60] fullerene derivatives with different substituents
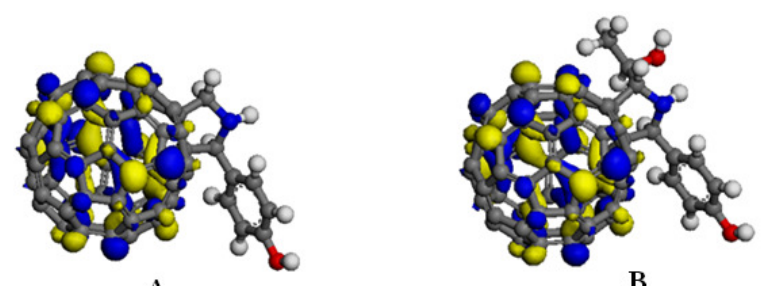

B

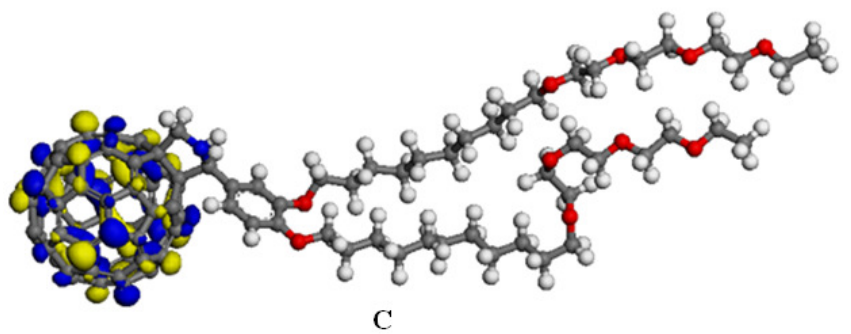

Fig. 4. LUMO of three [60] fullerene derivatives with different substituents

\begin{tabular}{|c|c|c|c|}
\hline \multicolumn{4}{|c|}{$\begin{array}{l}\text { TABLE-1 } \\
\text { FRONTIER ORBITAL ENERGY OF [60] FULLERENE AND THREE [60] FULLERENE } \\
\text { DERIVATIVES WITH DIFFERENT SUBSTITUENTS }\end{array}$} \\
\hline Compound & HOMO $(\mathrm{eV})$ & LUMO $(\mathrm{eV})$ & $\Delta \mathrm{E}(\mathrm{eV})$ \\
\hline & -0.212043 & -0.150671 & 0.061372 \\
\hline & -0.195875 & -0.142078 & 0.053797 \\
\hline & -0.196173 & -0.142826 & 0.053347 \\
\hline & -0.192779 & -0.139204 & 0.053575 \\
\hline
\end{tabular}


The energy gaps $(\Delta \mathrm{E})$ between the highest occupied molecular orbital (HOMO) and the lowest unoccupied molecular orbital (LUMO) were also calculated by Dmol3 (Table-1). The value of $\Delta \mathrm{E}$ is the largest when [60] fullerene without substituents and the $\Delta \mathrm{E}$ is the smallest when the substituents number of pyrrolidine of [60] fullerene derivatives is the most, the value is $0.053347 \mathrm{eV}$. The possible reason is that the electron density of pyrrolidine with more substituents is the highest and the electron easily move [60] fullerene.

Bond length and angle of [60] fullerene derivatives with different substituents: Effect of different substituents on geometrical structure of [60] fullerene derivatives also reflects the variety of bond length and bond angle. Tables 2 and 3 show the bond length and angle of [60] fullerene derivatives with different substituents. As seen in Table-2, the variety of bond length is distinct under the pyrrolidine with two substituents of [60] fullerene derivatives, the reason is that substituents may compress bond. It is this reason that makes bond angle of $\mathrm{A}, \mathrm{B}$ and $\mathrm{C}$ evidently change. Especially, bond angle of $\angle \mathrm{C} 2 \mathrm{~N} 3 \mathrm{H} 4$ is the most obvious.

TABLE-2

BOND LENGTH OF [60] FULLERENE DERIVATIVES WITH DIFFERENT SUBSTITUENTS

\begin{tabular}{cccc}
\hline Bond length $(\mathrm{nm})$ & A & B & C \\
\hline C1-C2 & 1.546 & 1.558 & 1.544 \\
C2-N3 & 1.435 & 1.440 & 1.432 \\
N3-H4 & 1.028 & 1.034 & 1.028 \\
N3-C5 & 1.437 & 1.440 & 1.442 \\
C5-C6 & 1.564 & 1.559 & 1.565 \\
C5-C7 & 1.484 & 1.486 & 1.485 \\
\hline
\end{tabular}

TABLE-3

BOND ANGLE OF [60] FULLERENE DERIVATIVES WITH DIFFERENT SUBSTITUENTS

\begin{tabular}{cccc}
\hline Bond angle $\left({ }^{\circ}\right)$ & $\mathrm{A}$ & $\mathrm{B}$ & $\mathrm{C}$ \\
\hline$\angle \mathrm{C} 1 \mathrm{C} 2 \mathrm{~N} 3$ & 102.864 & 102.877 & 102.468 \\
$\angle \mathrm{C} 2 \mathrm{~N} 3 \mathrm{H} 4$ & 113.660 & 108.838 & 114.192 \\
$\angle \mathrm{N} 3 \mathrm{C} 5 \mathrm{C} 6$ & 101.429 & 101.541 & 101.132 \\
$\angle \mathrm{N} 3 \mathrm{C} 5 \mathrm{C} 7$ & 115.034 & 114.443 & 112.873 \\
$\angle \mathrm{C} 6 \mathrm{C} 5 \mathrm{C} 7$ & 113.070 & 112.749 & 117.719 \\
\hline
\end{tabular}

\section{ACKNOWLEDGEMENTS}

This work was supported by China Postdoctoral Science Foundation (Project No. 2013M531937), Key Project of Chinese Ministry of Education (Project No. 212144), Natural Science Foundation Project of CQ CSTC(Project No. cstc2012jjA50001), Postdoctoral Science Foundation Project of ChongQing (Project No. XM20120035), Foundation of ChongQing Municipal Education Commission (Project No. KJ131202) and ChongQing University of Arts and Sciences (Project No. R2012CH10, 2012PYXM04).

\section{REFERENCES}

1. W. Kang, M. Kitamura and Y. Arakawa, Org. Electron., 14, 644 (2013).

2. M.Q. Yang, N. Zhang and Y.J. Xu, ACS Appl. Mater. Interfac., 5, 1156 (2013).

3. N. Ding, N. Kunugita, T. Ichinose, Y. Song, M. Yokoyama, K. Arashidani and Y.Yoshida, J. Hazard. Mater, 194, 324 (2011).

4. R.V. Belosludov, M. Sluiter, Z.-Q. Li and Y. Kawazoe, Chem. Phys. Lett., 312, 299 (1999).

5. H.S. Kang, J. Comput. Chem., 28, 594 (2007). 